\title{
High resolution 3-D velocity structure in the source region of the 2000 Western Tottori Earthquake in southwestern Honshu, Japan using very dense aftershock observations
}

\author{
Takuo Shibutani ${ }^{1}$, Hiroshi Katao ${ }^{1}$, and \\ Group for the dense aftershock observations of the 2000 Western Tottori Earthquake ${ }^{2}$ \\ ${ }^{1}$ Disaster Prevention Research Institute, Kyoto University, Kyoto 611-0011, Japan \\ ${ }^{2}$ The members of the group are listed at the end of this paper.
}

(Received June 24, 2004; Revised May 17, 2005; Accepted July 6, 2005)

\begin{abstract}
We carried out high density aftershock observations a week after the 2000 Western Tottori Earthquake for 40 days. We deployed 72 seismic stations in and around the aftershock area. The average spacing of the stations in the aftershock area was 4-5 km. We determined accurate hypocenters and focal mechanisms for $\sim 1,000$ aftershocks and obtained a high resolution 3-D velocity structure in the source region. High $P$ and $S$ wave velocity anomalies $(>4 \%)$ near the southeasternmost aftershock area at $2 \mathrm{~km}$ depth correlated with Jurassic to Late Cretaceous plutonic and high pressure metamorphic rocks. The depth distribution of the $P$ and $S$ wave velocities along the mainshock fault showed that high velocity anomalies were located at the shallow southeastern edge and the deeper central part of the aftershock area. The ratio between $P$ and $S$ wave velocities in the high velocity anomalies was a little higher $(\sim 1.75)$ than the average value $(\sim 1.70)$ in the upper crust. These results indicate that the high velocity anomalies could correspond to the plutonic or metamorphic rocks. The distributions of the high velocity anomalies and large slips of the mainshock were complementary. These suggest that the high velocity anomalies could be stronger than the surrounding materials and might behave as barriers to the mainshock rupture.
\end{abstract}

Key words: The 2000 Western Tottori Earthquake, aftershock observation, 3-D velocity structure, aftershock distribution, focal mechanisms.

\section{Introduction}

A large earthquake occurred on 6 October 2000 in the western part of Tottori Prefecture, southwestern Honshu, Japan. The Japan Meteorological Agency (JMA) magnitude $(\mathrm{Mj})$ of the mainshock was 7.3, while the moment magnitude was estimated as 6.6 (Fukuyama et al., 2001). It injured nearly 100 people and damaged more than 1,500 houses in and around the source area.

A quick report on this earthquake was compiled by Umeda et al. (2001). Ohmi et al. (2002) provided detailed descriptions on the focal mechanism of the mainshock and the aftershock distribution of this event. The rupture process during the mainshock was studied by Sekiguchi and Iwata (2001) and Iwata and Sekiguchi (2002).

This earthquake was preceded by swarm-like seismic activity in 1989, 1990 and 1997 during which there were six $\mathrm{Mj} \approx 5$ earthquakes. The relation between these preceding swarms and the occurrence of the 2000 Western Tottori Earthquake was investigated by Shibutani et al. (2002). They found that the preceding swarms occurred on the same fault plane as that of the mainshock in 2000 and that the area of the preceding activity did not overlap with the area of large slip of the mainshock.

Copyright (c) The Society of Geomagnetism and Earth, Planetary and Space Sciences (SGEPSS); The Seismological Society of Japan; The Volcanological Society of Japan; The Geodetic Society of Japan; The Japanese Society for Planetary Sciences; TERRAPUB
Following the mainshock we carried out a dense aftershock observation with 72 stations from 13 October that continued for one and a half months. The purpose of this observation was to determine precisely the locations and the focal mechanism solutions of the aftershocks, to obtain a detailed 3-D velocity structure in the source region by means of tomographic inversions of $P$ and $S$ travel time data, and to image 3-D distributions of reflectors and scatterers by utilizing array analyses of reflected and scattered waves.

In this paper we describe the field observations, and show the results of the aftershock distribution, the focal mechanisms of the aftershocks and the 3-D velocity structure in the source region.

Hirahara et al. (1992) studied the relationship between the slip distribution of the 1984 Western Nagano Prefecture Earthquake $(\mathrm{Mj}=6.9)$ and the $3-\mathrm{D}$ velocity structure in the source region. They found that the area with large dislocations corresponded to low velocity anomalies on the fault plane. Zhao et al. (1996) studied the 1995 Hyogoken Nanbu Earthquake (Kobe Earthquake, $\mathrm{Mj}=7.3$ ) and found low velocity anomalies with high $V p / V s$ values near the hypocenter $(V p$ and $V s$ indicate the $P$ and $S$ wave velocities, respectively), and suggested that fluids might play an important role in the initiation of the mainshock. We checked whether such features could be recognized for the 2000 Western Tottori Earthquake. We also investigated 


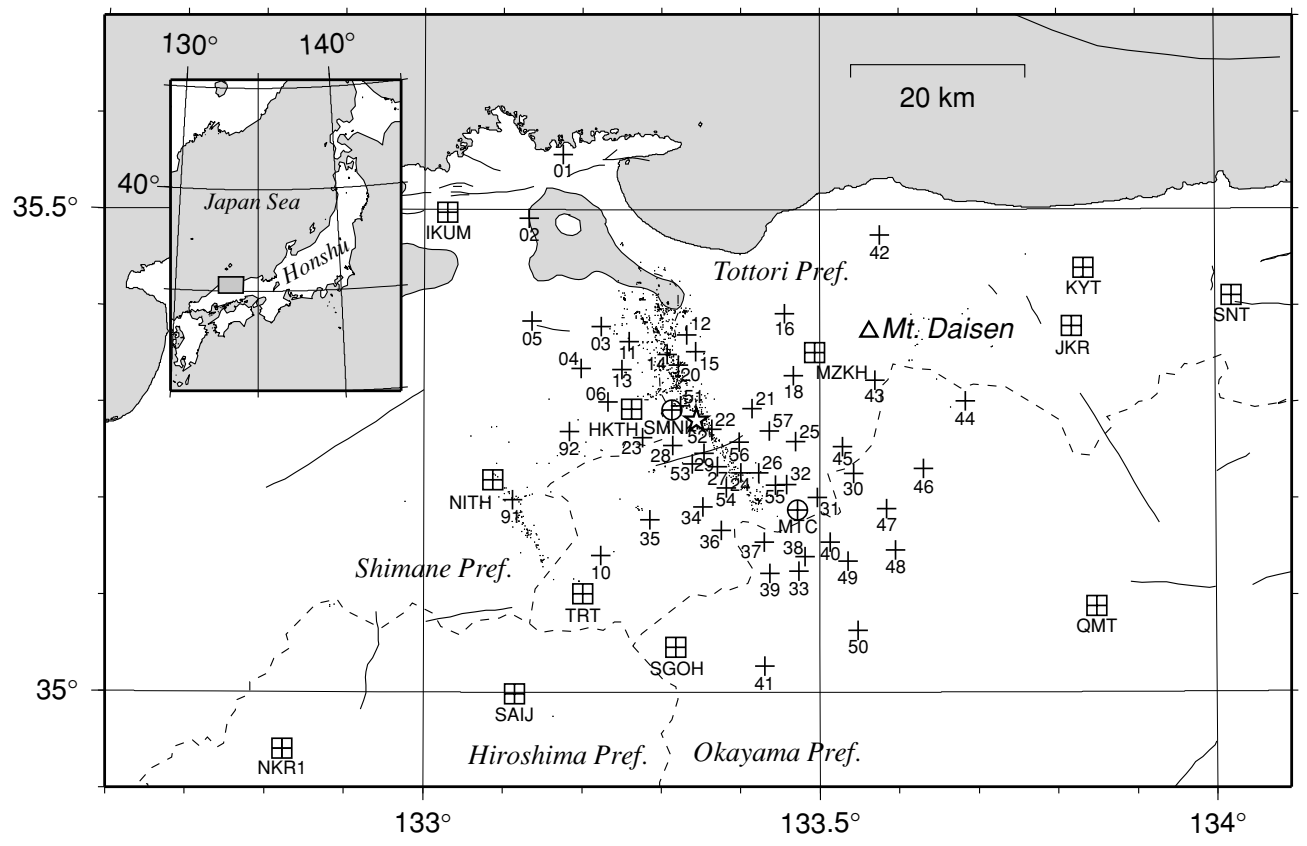

Fig. 1. Map showing the location of the stations (cross: temporary onsite recording, cross with circle: temporary telemetered, cross with square: permanent telemetered) used in the aftershock observation of the 2000 Western Tottori Earthquake. The part of the codes "wt" common to the temporary onsite recording stations is omitted in this figure. Dots denote the aftershocks used in this study. The star shows the starting point of the mainshock rupture. The triangle denotes Mt. Daisen, a Quaternary volcano which has been inactive for 20,000 years. The dashed lines indicate the borders of prefectures. Active faults are shown by solid lines.

the relationship between the 3-D velocity structure and the geology in the source region. Finally, we want to clarify the relationship between the source process of the 2000 Western Tottori Earthquake and the 3-D structure.

\section{Aftershock Observations}

We deployed 57 stations with onsite recording and 2 telemetered stations in and around the aftershock area from 13 October to early in December. We also used the data from 13 permanent stations together with the data from the temporary stations. As shown in Fig. 1, the stations were placed to densely cover the aftershock area along the main fault. The average station spacing was $4-5 \mathrm{~km}$ near the center and 10-20 km near the periphery. The area of the stations extended over $65 \mathrm{~km}$ in the NW-SE direction and $100 \mathrm{~km}$ in the NE-SW direction. Details of the station information are listed in Table 1.

At most of the stations, we installed 3 component shortperiod velocity seismometers (Lennartz LE3D [1 Hz]; Sercel (Mark Products) L22D [2 Hz]; L28B [4.5 Hz]; L15 [4.5 $\mathrm{Hz}]$ ), and recorded continuously with a sampling rate of 100 $\mathrm{Hz}$ (Clovertec DAT-2GC [16-bit A/D]). The GPS time information was also recorded every 6 hours for time corrections.

More than 70 people took part in this aftershock deployment from Kyoto University, University of Tokyo, Tohoku University, Hokkaido University, Ehime University, Yamagata University, Tottori University and Kyushu University. All the participants are listed at the end of this paper.

\section{Initial Hypocenter Determinations}

We selected local events $(\mathrm{Mj} \geq 1.7)$ from the JMA cata$\log$ which occurred in and around the aftershock area during the observation period, and extracted corresponding waveforms from the continuously recorded data.

We manually picked the arrival times of the $P$ and $S$ waves and the polarity of the $P$ wave for 1,087 local events which occurred from 15 October to 25 October. The onsets of the $P$ waves were sharp for most of the waveforms, so that we could read the arrival times with high accuracy (typically $\sim 0.01 \mathrm{~s}$ ). The $P$ arrival times were read at more than 50 stations for $94 \%$ of the analyzed aftershocks. $S$ arrival times were picked on one of the horizontal components. Most of the $S$ wave onsets were also sharp and were read at more than 45 stations for $90 \%$ of the analyzed aftershocks.

The hypocenters of the aftershocks were initially determined using HYPOMH (Hirata and Matsu'ura, 1987) for a 1-D velocity model shown by the dotted lines in Fig. 2, which is used routinely for this region (Oike, 1975; Ohmi et al., 2001).

\section{1-D Velocity Models and Station Corrections}

With the manually picked arrival times of the $P$ and $S$ waves and the initially determined origin times and hypocenters, we determined simultaneously the hypocentral parameters for the 1,087 events, 1 -D velocity models of the $P$ and $S$ waves and the travel time corrections for 68 stations (Table 1) using a Joint Hypocenter Determination (JHD) method (Kissling et al., 1994). Five stations were not used in the JHD relocation and the tomographic inversion (shown in the next section) because of insufficient time accuracy. In this inversion the weight of the $S$ waves was $50 \%$ of that of the $P$ waves, and the damping factors were set to 0.01 for the hypocentral parameters, 1.0 for the velocity parameters and 0.1 for the station correction parameters. 
Table 1. List of the stations deployed in the aftershock observation and the station corrections obtained by the JHD method.

\begin{tabular}{|c|c|c|c|c|c|c|}
\hline Code & Longitude & Latitude & Height, $\mathrm{m}$ & $\Delta P, \mathrm{~s}$ & $\Delta S, \mathrm{~s}$ & Remarks \\
\hline wt01 & 133.1755 & 35.5572 & 10 & 0.216 & 0.348 & $\mathrm{TF}$ \\
\hline wt02 & 133.1326 & 35.4912 & 20 & 0.465 & 0.923 & TF \\
\hline wt03 & 133.2236 & 35.3791 & 60 & 0.071 & 0.121 & $\mathrm{TF}$ \\
\hline wt04 & 133.1984 & 35.3353 & 660 & -0.015 & -0.085 & $\mathrm{TF}$ \\
\hline wt05 & 133.1366 & 35.3844 & 400 & 0.114 & 0.178 & $\mathrm{TF}$ \\
\hline wt06 & 133.2325 & 35.3007 & 190 & 0.036 & 0.059 & $\mathrm{TF}$ \\
\hline wt07 & 133.2123 & 35.1893 & 680 & - & - & $\mathrm{TF}$ \\
\hline wt08 & 133.3127 & 35.3179 & 120 & - & - & $\mathrm{TF}$ \\
\hline wt91 & 133.1121 & 35.1995 & 460 & -0.024 & -0.077 & $\mathrm{TF},-10 / 2211: 30$ \\
\hline wt92 & 133.1836 & 35.2701 & 340 & 0.003 & -0.041 & TF, $10 / 2213: 16-$ \\
\hline wt10 & 133.2238 & 35.1415 & 545 & 0.010 & -0.014 & $\mathrm{TF}$ \\
\hline wt11 & 133.2591 & 35.3634 & 40 & 0.092 & 0.168 & $\mathrm{TF}$ \\
\hline wt12 & 133.3320 & 35.3702 & 180 & 0.133 & 0.218 & $\mathrm{TF}$ \\
\hline wt13 & 133.2502 & 35.3342 & 140 & 0.041 & 0.054 & $\mathrm{TF}$ \\
\hline wt14 & 133.3076 & 35.3500 & 70 & 0.073 & 0.114 & $\mathrm{TF}$ \\
\hline wt15 & 133.3430 & 35.3527 & 80 & 0.066 & 0.171 & $\mathrm{TF}$ \\
\hline wt16 & 133.4555 & 35.3921 & 185 & 0.076 & 0.213 & TF \\
\hline wt17 & 133.4079 & 35.3371 & 140 & - & - & $\mathrm{TF}$ \\
\hline wt18 & 133.4668 & 35.3279 & 300 & 0.044 & 0.144 & $\mathrm{TF}$ \\
\hline wt19 & 133.3649 & 35.3224 & 110 & - & - & $\mathrm{TF}$ \\
\hline wt20 & 133.3214 & 35.3389 & 70 & 0.079 & 0.144 & $\mathrm{TF}$ \\
\hline wt21 & 133.4145 & 35.2940 & 140 & 0.007 & -0.031 & $\mathrm{TF}$ \\
\hline wt22 & 133.3634 & 35.2723 & 330 & 0.005 & -0.043 & $\mathrm{TF}$ \\
\hline wt 23 & 133.2764 & 35.2638 & 360 & -0.006 & -0.090 & $\mathrm{TF}$ \\
\hline wt24 & 133.4002 & 35.2274 & 410 & 0.033 & 0.129 & TF \\
\hline wt 25 & 133.4695 & 35.2600 & 190 & -0.014 & -0.061 & $\mathrm{TF}$ \\
\hline wt26 & 133.4233 & 35.2275 & 230 & 0.051 & 0.146 & $\mathrm{TF}$ \\
\hline wt27 & 133.3708 & 35.2337 & 550 & 0.000 & -0.040 & $\mathrm{TF}$ \\
\hline wt 28 & 133.3142 & 35.2557 & 460 & 0.095 & 0.206 & $\mathrm{TF}$ \\
\hline wt 29 & 133.3539 & 35.2474 & 405 & 0.005 & -0.012 & $\mathrm{TF}$ \\
\hline wt30 & 133.5426 & 35.2269 & 760 & -0.116 & -0.269 & $\mathrm{TF}$ \\
\hline wt31 & 133.4969 & 35.2020 & 420 & -0.107 & -0.215 & $\mathrm{TF}$ \\
\hline wt32 & 133.4582 & 35.2150 & 260 & -0.053 & -0.142 & $\mathrm{TF}$ \\
\hline wt33 & 133.4739 & 35.1256 & 660 & -0.098 & -0.135 & $\mathrm{TF}$ \\
\hline wt34 & 133.3522 & 35.1923 & 260 & 0.019 & -0.034 & $\mathrm{TF}$ \\
\hline wt35 & 133.2856 & 35.1787 & 380 & 0.022 & -0.023 & $\mathrm{TF}$ \\
\hline wt36 & 133.3759 & 35.1676 & 445 & -0.018 & -0.117 & $\mathrm{TF}$ \\
\hline wt37 & 133.4302 & 35.1554 & 610 & -0.030 & -0.015 & $\mathrm{TF}$ \\
\hline wt38 & 133.4813 & 35.1406 & 770 & -0.122 & -0.206 & $\mathrm{TF}$ \\
\hline wt39 & 133.4370 & 35.1233 & 520 & -0.090 & -0.142 & $\mathrm{TF}$ \\
\hline wt40 & 133.5130 & 35.1554 & 620 & -0.151 & -0.258 & $\mathrm{TF}$ \\
\hline wt41 & 133.4303 & 35.0271 & 360 & -0.043 & -0.161 & $\mathrm{TF}$ \\
\hline wt42 & 133.5761 & 35.4736 & 115 & 0.191 & 0.415 & $\mathrm{TF}$ \\
\hline wt43 & 133.5695 & 35.3234 & 725 & 0.038 & 0.143 & $\mathrm{TF}$ \\
\hline wt44 & 133.6839 & 35.3015 & 560 & 0.071 & 0.401 & $\mathrm{TF}$ \\
\hline wt45 & 133.5287 & 35.2543 & 335 & -0.106 & -0.254 & $\mathrm{TF}$ \\
\hline wt46 & 133.6311 & 35.2319 & 600 & -0.137 & -0.255 & $\mathrm{TF}$ \\
\hline wt47 & 133.5844 & 35.1901 & 550 & -0.122 & -0.274 & $\mathrm{TF}$ \\
\hline wt 48 & 133.5956 & 35.1476 & 525 & -0.071 & -0.094 & $\mathrm{TF}$ \\
\hline wt49 & 133.5353 & 35.1359 & 520 & -0.079 & -0.112 & $\mathrm{TF}$ \\
\hline wt50 & 133.5481 & 35.0643 & 420 & -0.102 & -0.189 & $\mathrm{TF}$ \\
\hline wt51 & 133.3242 & 35.2966 & 170 & 0.015 & -0.030 & $\mathrm{TF}$ \\
\hline wt52 & 133.3455 & 35.2826 & 190 & 0.017 & -0.021 & $\mathrm{TF}$ \\
\hline$w+53$ & 133.3389 & 35.2366 & 430 & 0.044 & 0.091 & $\mathrm{TF}$ \\
\hline$w t 54$ & 133.3818 & 35.2116 & 255 & 0.013 & 0.017 & $\mathrm{TF}$ \\
\hline wt55 & 133.4439 & 35.2144 & 260 & -0.040 & -0.117 & $\mathrm{TF},-11 / 0716: 50$ \\
\hline wt56 & 133.3980 & 35.2590 & 240 & 0.003 & -0.024 & $\mathrm{TF}$ \\
\hline wt57 & 133.4364 & 35.2709 & 360 & 0.011 & 0.066 & $\mathrm{TF}$ \\
\hline SMNK & 133.3136 & 35.2924 & 210 & 0.001 & -0.066 & $\mathrm{TN}$ \\
\hline MTC & 133.4724 & 35.1890 & 430 & -0.114 & -0.231 & $\mathrm{TN}$ \\
\hline KYT & 133.8338 & 35.4392 & 100 & 0.119 & 0.178 & $\mathrm{P}, \mathrm{KU}$ \\
\hline SNT & 134.0203 & 35.4105 & 200 & 0.175 & 0.375 & $\mathrm{P}, \mathrm{KU}$ \\
\hline TRT & 133.2016 & 35.1022 & 480 & 0.002 & -0.048 & $\mathrm{P}, \mathrm{KU}$ \\
\hline QMT & 133.8491 & 35.0885 & 330 & -0.071 & -0.121 & $\mathrm{P}, \mathrm{KU}$ \\
\hline NKR1 & 132.8228 & 34.9410 & 330 & -0.004 & -0.134 & $\mathrm{P}, \mathrm{UT}$ \\
\hline IKUM & 133.0300 & 35.4967 & 20 & 0.411 & 0.804 & P, JMA \\
\hline JKR & 133.8200 & 35.3783 & 180 & 0.083 & 0.132 & P, JMA \\
\hline SAIJ & 133.1150 & 34.9983 & 480 & -0.025 & -0.043 & P, JMA \\
\hline HINH & 133.3936 & 35.2278 & 308 & - & - & $\mathrm{P}, \mathrm{NIED}$ \\
\hline MZKH & 133.4942 & 35.3522 & 222 & -0.016 & -0.096 & P, NIED \\
\hline HKTH & 133.2628 & 35.2931 & 54 & 0.033 & -0.026 & P, NIED \\
\hline NITH & 133.0883 & 35.2203 & 239 & 0.041 & -0.016 & P, NIED \\
\hline $\mathrm{SGOH}$ & 133.3196 & 35.0461 & 461 & -0.014 & -0.135 & $\mathrm{P}, \mathrm{NIED}$ \\
\hline
\end{tabular}

$\Delta P$ and $\Delta S$ denote the station corrections (delays) for the $P$ and $S$ times, respectively. The values are relative to the $P$ time of station wt27. TF: temporary station with onsite recording; TN: temporary telemetered station; P: permanent telemetered station. KU: RCEP, DPRI, Kyoto University; UT: ERI, University of Tokyo; JMA: Japan Meteorological Agency; NIED: National Research Institute for Earth Science and Disaster Prevention. 


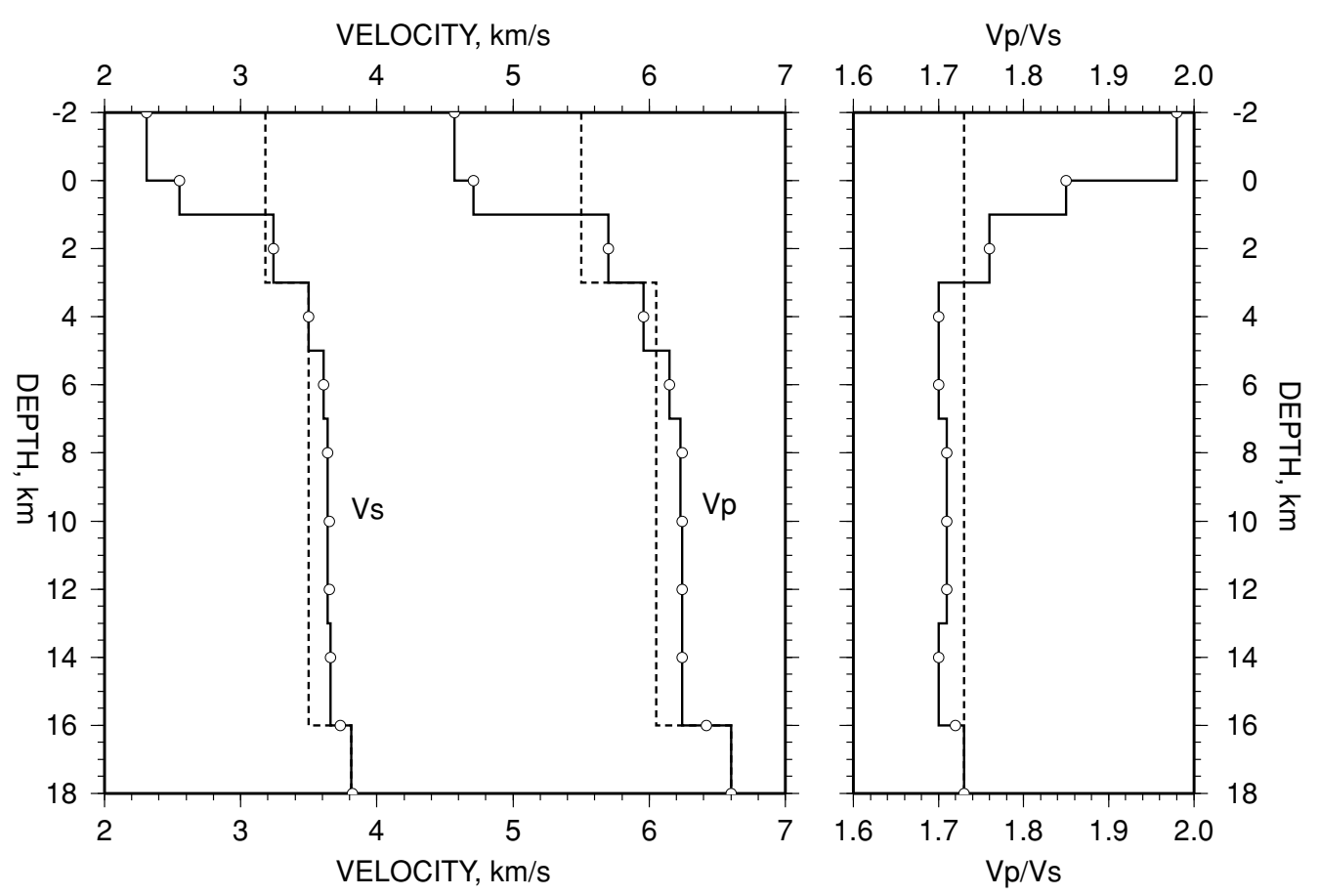

Fig. 2. 1-D models of the $P$ and $S$ wave velocities from -2 to $18 \mathrm{~km}$ depth. The $V p / V s$ is also shown on the right side. The broken lines indicate the velocity models which were used for the initial determination of the aftershocks. The solid lines denote the velocity models which were obtained as the result of the joint hypocenter determination (JHD) method (see the text for details). The open circles indicate the depth points of the initial models for the tomographic inversion.
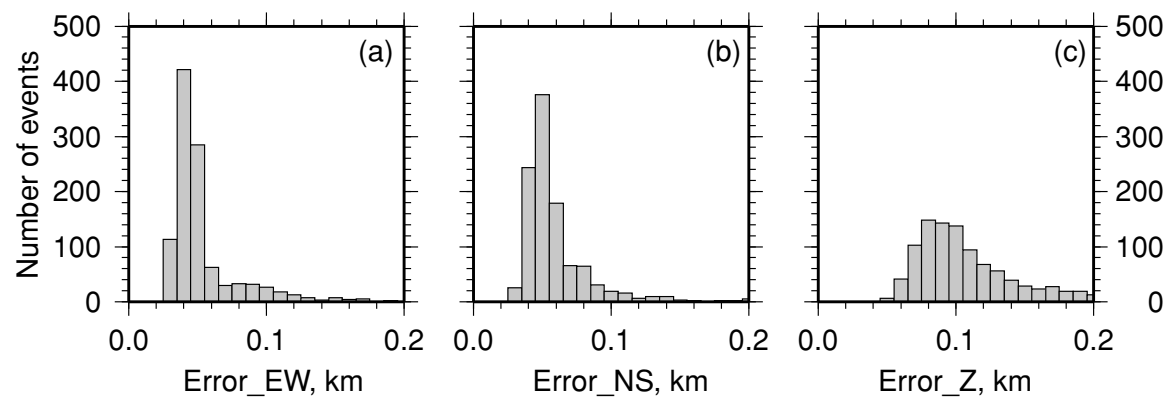

Fig. 3. Histograms of the errors in the hypocenters of the aftershocks relocated with the JHD technique. (a) EW direction, (b) NS direction and (c) Z direction.

Furthermore, the damping factors of the velocity parameters were multiplied by 5 for the eighth layer $(13-16 \mathrm{~km})$ and 10 for the ninth layer $(\geq 16 \mathrm{~km})$. The velocity parameters of these layers were not well constrained because only a small number of rays passed through the layers. Low velocity layers were not allowed.

The root mean square (RMS) of the travel time residuals decreased from $0.177 \mathrm{~s}$ to $0.089 \mathrm{~s}$ and the variance reduction in the $1-\mathrm{D}$ inversion was $75 \%\left(=\left(1-\left(0.089^{2} / 0.177^{2}\right) \times\right.\right.$ 100).

Figure 3 shows histograms of the errors of the relocated hypocenters. The errors were smaller than $0.10 \mathrm{~km}(\mathrm{EW})$, $0.09 \mathrm{~km}(\mathrm{NS})$ and $0.21 \mathrm{~km} \mathrm{(Z)} \mathrm{for} \mathrm{more} \mathrm{than} 90 \%$ of the analyzed aftershocks. The errors were significantly improved as well as the hypocenters after the JHD relocation. The relocated hypocenters relative to the initial locations were at most $0.4 \mathrm{~km}$ in a $\mathrm{N} 30^{\circ} \mathrm{W}$ direction and $0.7 \mathrm{~km}$ shallower, for more than $60 \%$ of the analyzed aftershocks. On the other hand, the relocated hypocenters relative to the JMA hypocenters were at least $1.6 \mathrm{~km}$ in the same direction and $1.9 \mathrm{~km}$ shallower, for more than $60 \%$ of the analyzed aftershocks. The differences between the relocated hypocenters and the JMA hypocenters were much larger than those between the relocated hypocenters and the initial hypocenters. This indicates that the initial hypocenters were determined quite accurately because the distribution of the stations was dense and the travel time residuals, which should correspond to the station corrections, were not mismapped to biases in the hypocenters.

The resulting velocity models are shown by the solid lines in Fig. 2 and listed in Table 2. The $P$ wave velocity increases gradually from $5.96 \mathrm{~km} / \mathrm{s}$ at $3 \mathrm{~km}$ to $6.24 \mathrm{~km} / \mathrm{s}$ at $10 \mathrm{~km}$. The $S$ wave velocity also increases gradually from $3.50 \mathrm{~km} / \mathrm{s}$ at $3 \mathrm{~km}$ to $3.64 \mathrm{~km} / \mathrm{s}$ at $10 \mathrm{~km}$. The ratio of $V p$ to $V s$ is nearly constant, $1.70-1.71$, in this depth range. The resolutions are greater than 0.9 and the standard errors are smaller than $0.03 \mathrm{~km} / \mathrm{s}$.

The resolution of the first layer $(-2-0 \mathrm{~km})$ is small for 

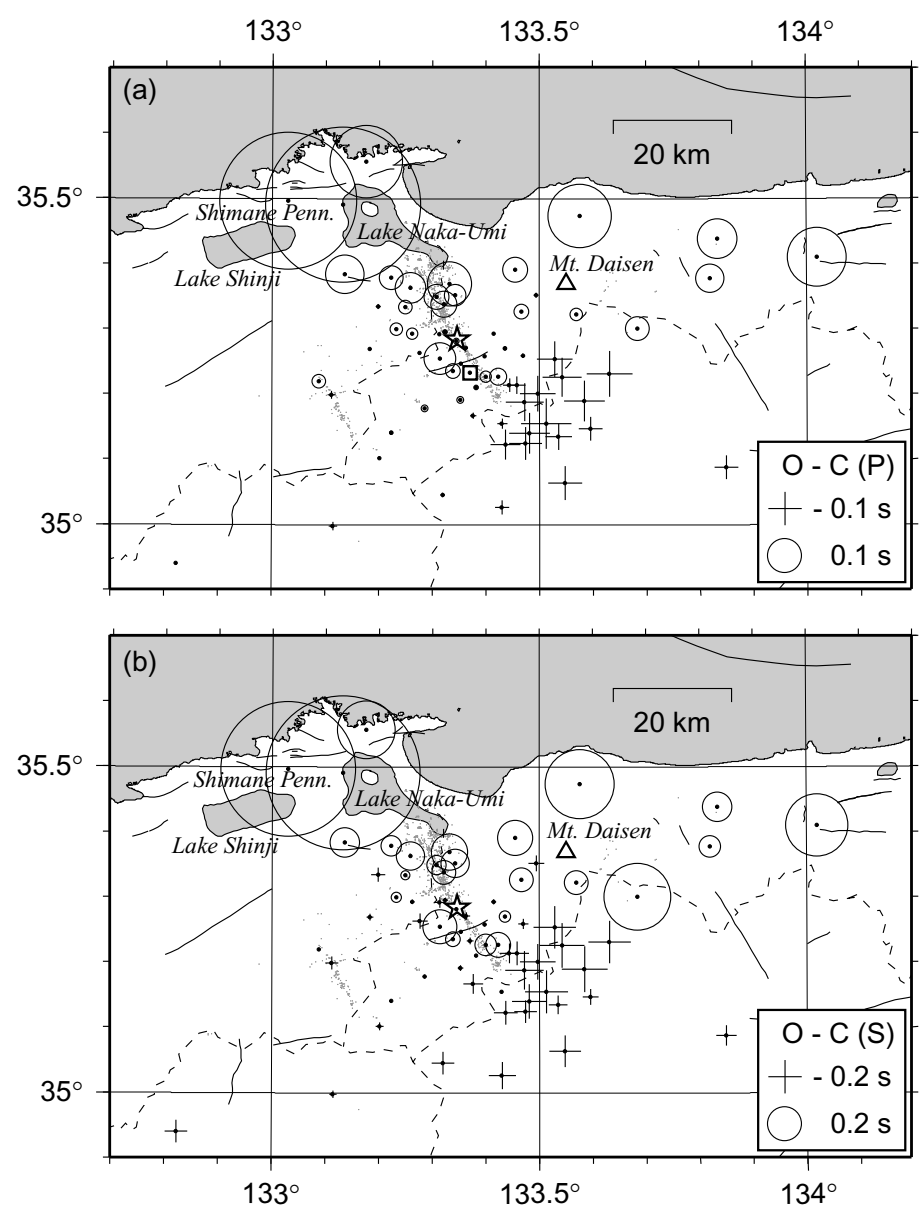

Fig. 4. Travel time corrections for the $P$ and $S$ waves derived from the JHD method. (a) $P$ wave and (b) $S$ wave. The values are relative to the $P$ time of station wt 27 which is indicated by being surrounded by the square in (a). Circles indicate positive residuals, while crosses indicate negative residuals. Reference sizes are shown in the insets. The star indicates the starting point of the mainshock rupture. The triangle denotes the peak of Mt. Daisen.

Table 2. 1-D velocity structure obtained by the JHD method.

\begin{tabular}{rrrcccccc}
\hline \multirow{2}{*}{ Layer } & \multirow{2}{*}{$\mathrm{D}, \mathrm{km}$} & \multicolumn{3}{c}{$P$ wave } & & \multicolumn{3}{c}{$S$ wave } \\
\cline { 3 - 5 } \cline { 7 - 8 } & & $\mathrm{V}, \mathrm{km} / \mathrm{s}$ & $\mathrm{SE}, \mathrm{km} / \mathrm{s}$ & $\mathrm{R}$ & & $\mathrm{V}, \mathrm{km} / \mathrm{s}$ & $\mathrm{SE}, \mathrm{km} / \mathrm{s}$ & $\mathrm{R}$ \\
\hline 1 & -2.0 & 4.57 & 0.024 & 0.102 & & 2.31 & 0.031 & 0.181 \\
2 & 0.0 & 4.71 & 0.038 & 0.411 & & 2.55 & 0.036 & 0.602 \\
3 & 1.0 & 5.70 & 0.008 & 0.992 & & 3.24 & 0.006 & 0.996 \\
4 & 3.0 & 5.96 & 0.004 & 0.998 & & 3.50 & 0.002 & 0.999 \\
5 & 5.0 & 6.15 & 0.004 & 0.998 & & 3.61 & 0.002 & 0.999 \\
6 & 7.0 & 6.23 & 0.005 & 0.996 & & 3.64 & 0.003 & 0.999 \\
7 & 10.0 & 6.24 & 0.026 & 0.906 & & 3.64 & 0.009 & 0.989 \\
8 & 13.0 & 6.24 & 0.003 & 0.006 & & 3.66 & 0.011 & 0.080 \\
9 & 16.0 & 6.60 & 0.000 & 0.000 & & 3.81 & 0.000 & 0.000 \\
\hline
\end{tabular}

$\mathrm{D}$ denotes the depth to the top of the layer. $\mathrm{V}$ indicates the wave velocity in the layer. SE and $\mathrm{R}$ are the standard error and the resolution of the velocity, respectively.

both the $V p$ and $V s$, which means that the velocities in the layer are not well constrained. This is partly because the rays in the first layer are nearly vertical and their proportion to the total length is small, and partly because of the trade off between the velocities in the first layer and the station corrections. However, $4.57 \mathrm{~km} / \mathrm{s}$ seems to be acceptable for the $P$ wave velocity in the surface layer in this area. Results from a refraction survey (Tottori Prefectural Government, 2004) showed that $V p$ in the surface layer ranged from 4.0 to $5.0 \mathrm{~km} / \mathrm{s}$.

The obtained station corrections for the $P$ and $S$ travel times are illustrated in Fig. 4 and listed in Table 1. The station corrections are relative to the $P$ time of station wt27, which is located in the area of the Neu Granitic Pluton (mentioned in section 8), and at which the travel time residual averaged over all the analyzed aftershocks is very small ( $0.01 \mathrm{~s}$ for $P$ and $0.08 \mathrm{~s}$ for $S$ ). Large positive residuals in both $P$ and $S$ travel times are found at stations in the Shimane Peninsula. They are due to thick sediments in the Shinji Graben in which Lake Naka-umi and Lake Shinji are located (Sawada et al., 2001). Other positive residuals are found around Mt. Daisen which is a Quaternary volcano 


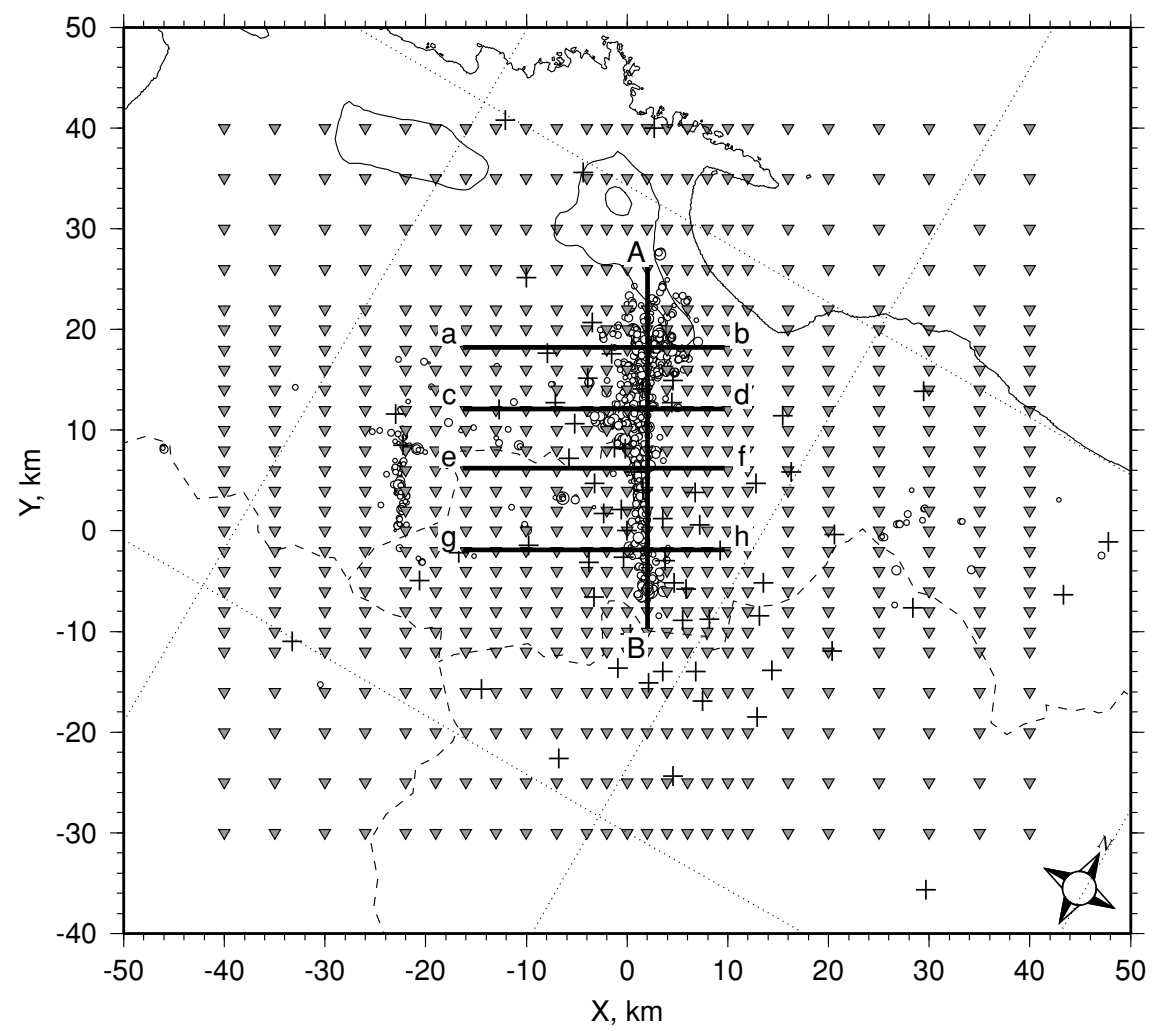

Fig. 5. Horizontal grid (inverted triangles) on which the $P$ and $S$ velocities are obtained in the travel-time tomography. The y-axis is rotated anticlockwise from North by $30^{\circ}$, so it is parallel to the distribution of the aftershocks. Cross sections of the resulting velocity structure along the thick lines AB, ab, cd, ef and gh are shown in Figs. 7 and 8. Open circles and crosses indicate the aftershocks and the stations, respectively.

and whose last activity was over 20,000 years ago (Tsukui, 1985).

\section{Seismic Tomography and 3-D Velocity Struc- ture}

We carried out a tomographic inversion of the travel times of the $P$ and $S$ waves. The data set was the same as we used in the 1-D inversion. 65,126 $P$ times and 58,130 $S$ times from the 1,087 events to the 68 stations were inverted for the 3-D heterogeneous structure of the $P$ and $S$ velocities. We used a program developed from SIMUL3M (Thurber, 1983). We extended it to use the $S$ times and obtain the $S$ velocity structure, similar to the $P$ wave analysis. The weights of the $S$ times were $0.76(\approx \sqrt{1 / 1.73})$ of the $P$ times. The distribution of the grid is shown in Fig. 5 with the events and the stations. The grid intervals are 2 $\times 2 \times 2 \mathrm{~km}$ in the vicinity of the aftershock area, so that small scale heterogeneities in the velocity structure can be resolved. The initial velocity model for the tomographic inversion was obtained by resampling the 1-D model obtained in the previous section, as shown in Fig. 2. The station corrections obtained in the previous section were subtracted from the observed $P$ and $S$ times. We carried out the first few runs of the tomographic inversions without the station corrections. The results showed, for example, that a large low velocity anomaly in the Shimane Peninsula was smeared southeastwards and downwards to $6 \mathrm{~km}$ depth. The depth distribution of velocity anomalies along the mainshock fault did not change, for runs with and without the station corrections. Therefore, we concluded that the station corrections should be subtracted from the $P$ and $S$ times before the tomographic inversion to obtain a better velocity structure of the surrounding region.

Eberhart-Phillips (1990) and Thurber (1993) pointed out that it is better to invert $P$ and $S$ times for $V p$ and $V p / V s$ rather than for $V p$ and $V s$ because the $S$ times tend to be fewer in number and lesser in quality than the $P$ times, so that $V s$ model solutions have lower resolution and greater uncertainty than $V p$. However, the $S$ times are comparable to the $P$ times in both number and quality in our data set as mentioned above. We successfully tuned the damping factors for $V p$ and $V s$ so that the resolutions of $V p$ and $V s$ became nearly equal (see Fig. 7(g) and (h)). Therefore, our choice to invert the $P$ and $S$ times for $V p$ and $V s$ is justified.

The RMS of the travel time residuals decreased from $0.089 \mathrm{~s}$ for the $1-\mathrm{D}$ inversion to $0.042 \mathrm{~s}$. The variance reduction in the tomographic inversion was $78 \%(=(1-$ $\left.\left.0.042^{2} / 0.089^{2}\right) \times 100\right)$. The total variance reduction in both inversions was $94 \%\left(=\left(1-0.042^{2} / 0.177^{2}\right) \times 100\right)$. The resulting velocity structure is shown in Figs. 6, 7, 8 and 11. In drawing these figures, we multiplied the perturbations of the velocities by the corresponding diagonal elements of the resolution matrix, considering the resolutions as the weights for the velocity perturbations. The diagonal elements of the resolution matrix have values between 0 and 1 . Values of 0 indicate that the model parameters are completely unresolved and the initial values should be taken. Values of 1 indicate that the corresponding model parameters are perfectly resolved and the final solutions can be calculated by 

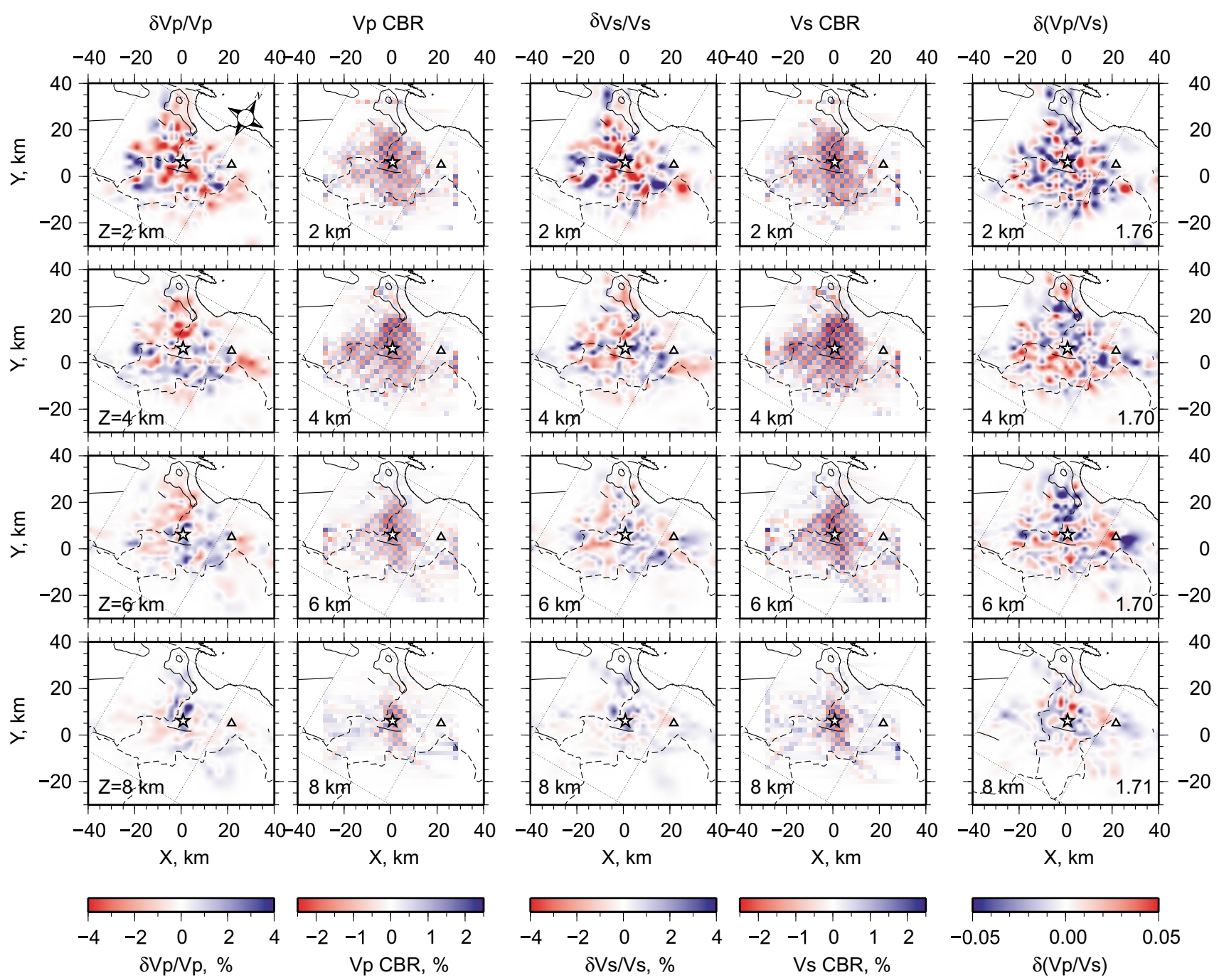

Fig. 6. $V p$ and $V s$ perturbations and their checker board resolutions at 2, 4,6 and $8 \mathrm{~km}$ depths (top to bottom). The horizontal distributions of $V p / V s$ are also shown in the rightmost figures. The number at the bottom right corner denotes the average value of $V p / V s$ at that depth. The star indicates the starting point of the mainshock rupture. The triangle denotes the peak of Mt. Daisen. Thin lines indicate active faults.

adding the perturbations to the initial values. Therefore, for all cases, we can calculate the final solutions by adding the weighted perturbations to the initial values. Since the resolutions of $V p$ and $V s$ are nearly equal as shown in Fig. 7(g) and (h), the differences between the $V p$ resolutions and the $V s$ resolutions have little effect on the perturbations of $V p / V s$. The checker board tests show how well an initial alternating pattern with $\pm 2.5 \%$ velocity anomaly can be recovered by the simulated tomography with the same set of paths as in the actual case.

Figure 6 shows the lateral distribution of the perturbations of $V p$ and $V s$ at the depths of 2, 4,6 and $8 \mathrm{~km}$. The checker board tests and the perturbation of $V p / V s$ are also shown in Fig. 6. At 2, 4 and $6 \mathrm{~km}$, the checker board tests show good recovery in relatively wide areas in and around the aftershock distribution for both $V p$ and $V s$. However, at $8 \mathrm{~km}$, the good recovery is limited to the vicinity of the aftershock area. The high and low velocity anomalies of $V p$ have, on the whole, the same patterns as those of $V s$. At $2 \mathrm{~km}$ quite a large low velocity anomaly is located southeastward of the starting point of the mainshock rupture.
At $4 \mathrm{~km}$ another low velocity anomaly exists northwestward of the mainshock starting point. In this low velocity anomaly, $|\delta V p / V p|$ is larger than $|\delta V s / V s|$ and consequently $V p / V s$ is low. The low velocity anomaly continues to $6 \mathrm{~km}$ in $V p$, but not in $V s$, which results in a low $V p / V s$ also at $6 \mathrm{~km}$. At 6 and $8 \mathrm{~km}$, the vicinity of the mainshock starting point shows a high velocity anomaly of $2-4 \%$. In the area around Daisen Volcano low velocity anomalies are found at various depths, however, the resolutions are unfortunately not sufficient to discuss in detail.

Figure 7 shows the depth distribution of $V p$ and $V s$ on the mainshock fault plane (along the line AB in Fig. 5). The checker board tests of $V p$ (e) and $V s$ (f) are good in almost the whole area of the aftershock distribution, where most of the diagonal components of the resolution matrix for both $V p(\mathrm{~g})$ and $V s(\mathrm{~h})$ are greater than 0.5 . High $V p$ anomalies with $4 \%$ or greater are located in patches at the central part and the southeastern edge of the aftershock distribution. In the high $V p$ patches, $V s$ also shows a high velocity anomaly and $V p / V s$ is $\sim 1.75$, which is significantly higher than the average value $(\sim 1.70)$ in the upper crust $(3-16$ 

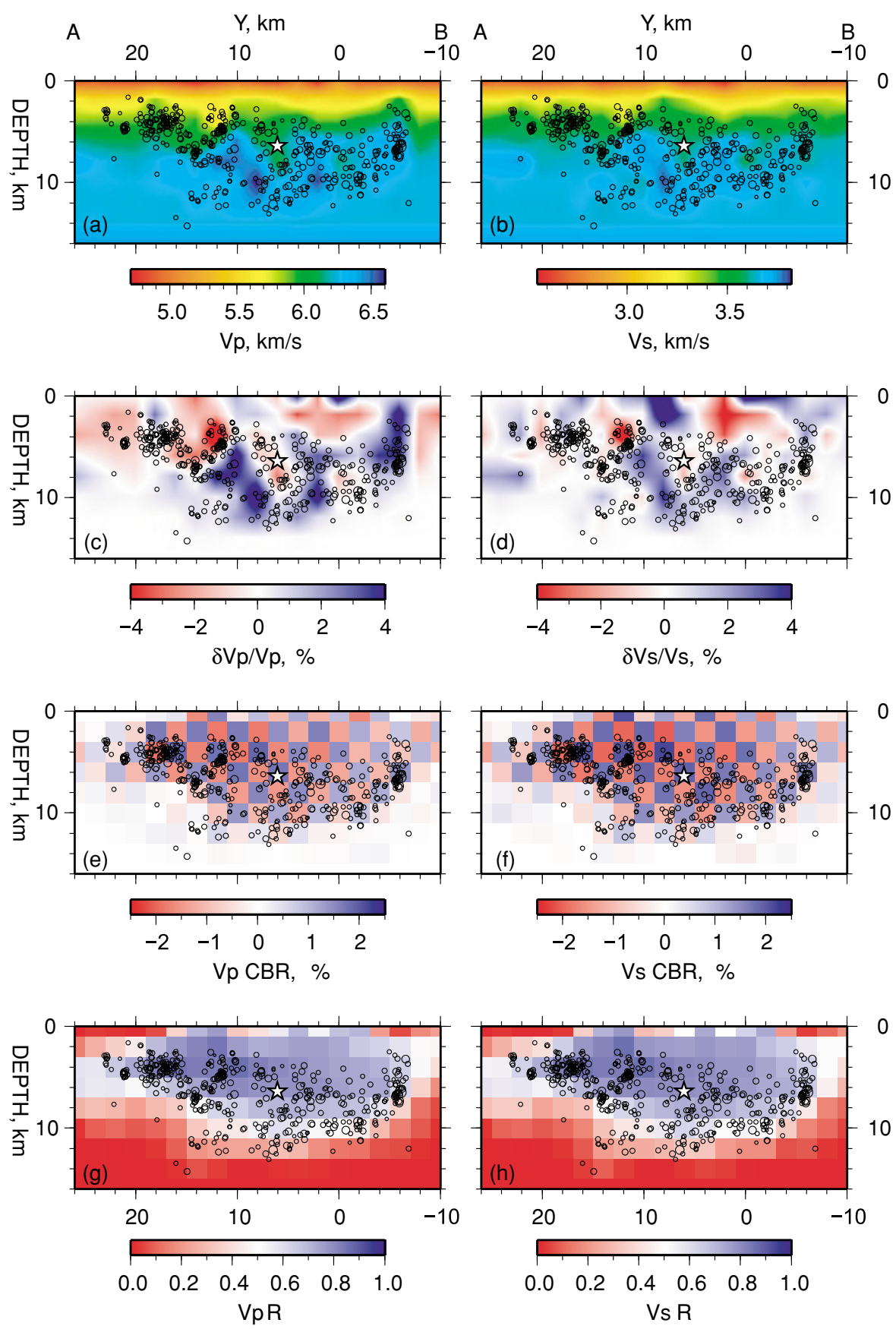

$\mathrm{Y}, \mathrm{km}$

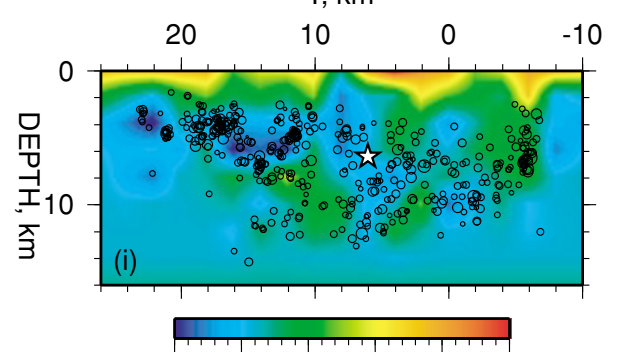

1.651 .701 .751 .801 .851 .90

$\mathrm{Vp} / \mathrm{Vs}$

Fig. 7. Cross sections of the resulting velocity structure along the line AB in Fig. 5, which is almost the same as the mainshock fault plane. The depth distributions of $V p$ (a), $V s$ (b), $V p$ perturbations (c), $V s$ perturbations (d), checker board resolutions of $V p$ (e) and $V s$ (f), diagonal components of the resolution matrix of $V p(\mathrm{~g})$ and $V s(\mathrm{~h})$, and $V p / V s$ (i). Open circles indicate the aftershocks which were located in the vicinity $( \pm 1 \mathrm{~km})$ of the fault plane. The star denotes the starting point of the mainshock rupture. 

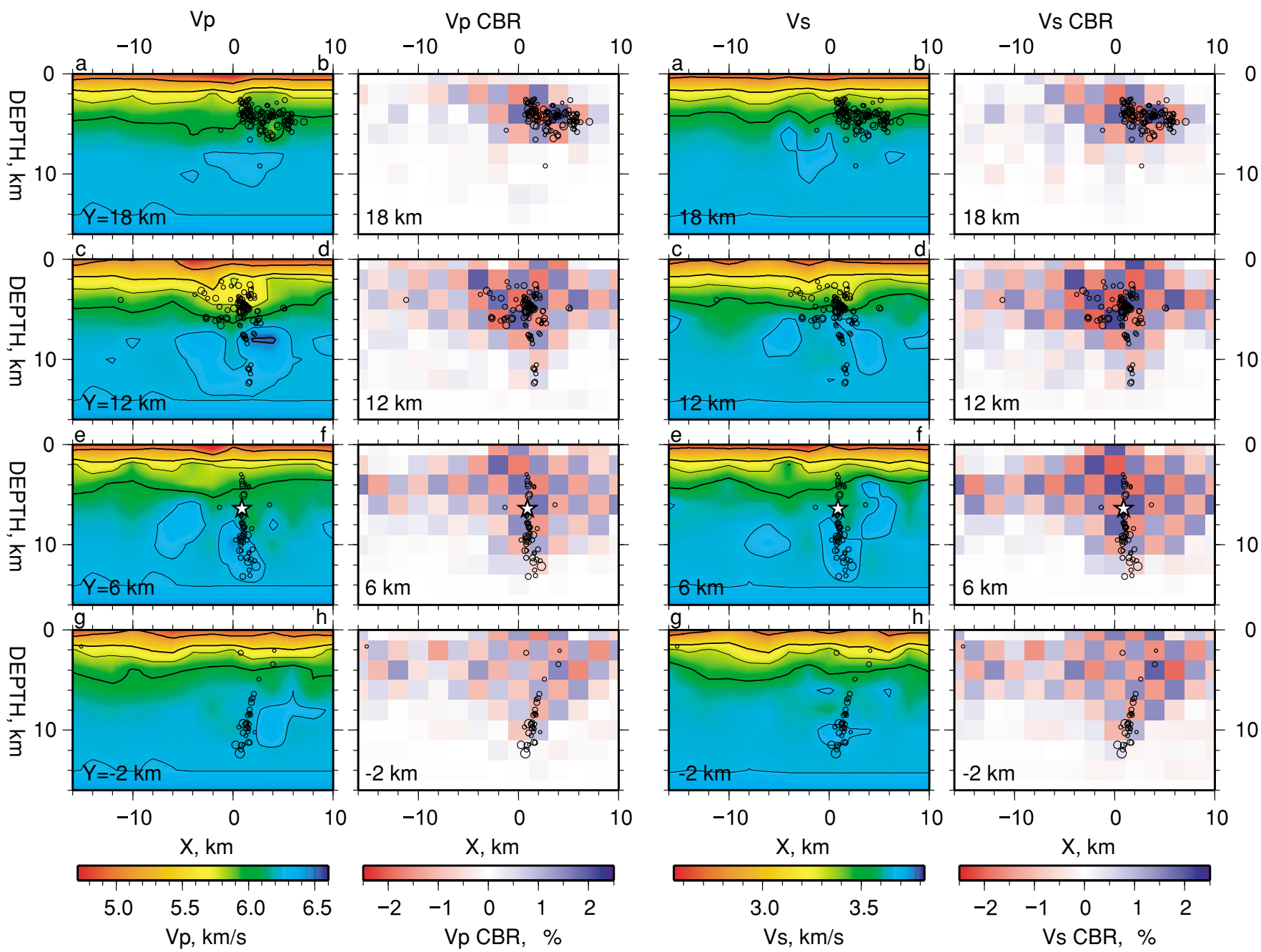

Fig. 8. Cross sections of the resulting velocity structure along the lines ab (uppermost figures), cd (figures in the second row), ef (figures in the third row) and gh (the lowermost figures) in Fig. 5. The figures in the columns from the left to the right show the depth distributions of $V p$, the checker board resolution of $V p, V s$ and the checker board resolution of $V s$. Open circles denote the aftershocks which occurred in the vicinity ( $\pm 1 \mathrm{~km}$ ) of each cross section. The star indicates the starting point of the mainshock rupture.

$\mathrm{km}$ ) in this region. The mainshock starting point is located in a low velocity anomaly which is surrounded by high velocity anomalies in the central part. At shallower depths to the southeast from the mainshock starting point, a low velocity anomaly extends horizontally, in which very few aftershocks occur. This low velocity anomaly corresponds very well with a large slip area $(2-3 \mathrm{~m})$ in the mainshock rupture process (Iwata and Sekiguchi, 2002).

Figure 8 includes four vertical sections along the lines $\mathrm{ab}$, cd, ef and gh in Fig. 5. The depth distribution of $V p$ and $V s$, and their checker board tests are shown in each vertical section. The vicinity of the mainshock fault shows a high velocity anomaly rather than a low velocity anomaly. The velocity field does not show significant changes between the northeast $\left(\mathrm{N}^{\circ} 0^{\circ} \mathrm{E}\right)$ and southwest $\left(\mathrm{S} 60^{\circ} \mathrm{W}\right)$ sides of the fault.

\section{Aftershock Distribution}

Figure 9 shows the distribution of aftershocks which were simultaneously determined in the tomographic inversion. As shown in the epicentral distribution and the depth distribution along the $\mathrm{Y}$ axis, the earthquakes are located in the vicinity of the fault plane of the mainshock and distribute from 2 to $13 \mathrm{~km}$ in depth in the southeastern twothirds of the aftershock area $(-7 \leq \mathrm{Y} \leq 15)$. In contrast, in the northwestern third of the aftershock area $(15 \leq \mathrm{Y} \leq 20)$, the earthquakes spread out spatially at shallower depths (2$7 \mathrm{~km})$. Only small slip $(<1 \mathrm{~m})$ was observed in the shallow depths $(<10 \mathrm{~km})$ of the northwestern third area and large slip ( $\geq 2 \mathrm{~m}$ ) was detected in the middle of the southeastern two-third area (Iwata and Sekiguchi, 2002). The aftershock activity in an hour after the mainshock was low in the northwestern area in comparison to the southeastern area (Ohmi et al., 2002). Therefore, the rupture directly associated to the mainshock was considered to occur in the southeastern area. This might be a cause of the differences of the aftershock distributions in the two areas. As shown in the cross section along $\mathrm{DD}^{\prime}$, the fault plane is almost vertical in the vicinity of the starting point of the mainshock (the star). However, it dips to the southwest in the farthest southeastern part of the aftershock area as shown in the cross sections along $\mathrm{EE}^{\prime}$ and $\mathrm{FF}^{\prime}$. The aftershocks branch to the southwest at $\mathrm{Y}=11 \mathrm{~km}$ as shown in the epicentral distribution and the cross section along $\mathrm{CC}^{\prime}$. 


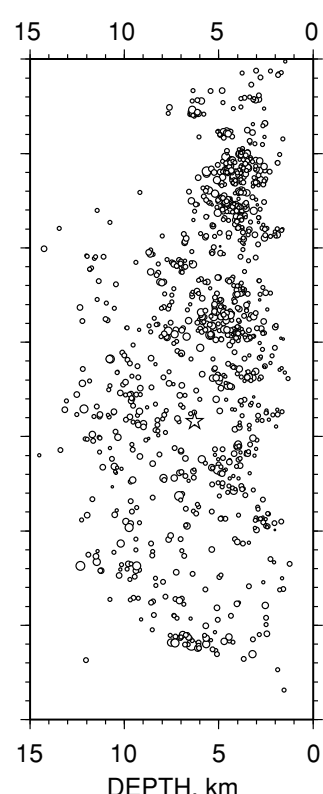

(a)

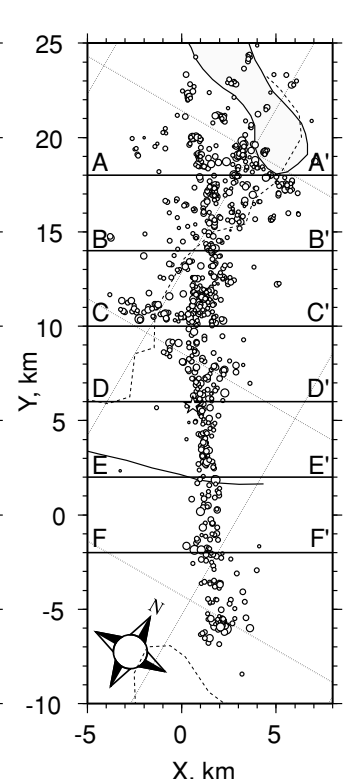

(b)
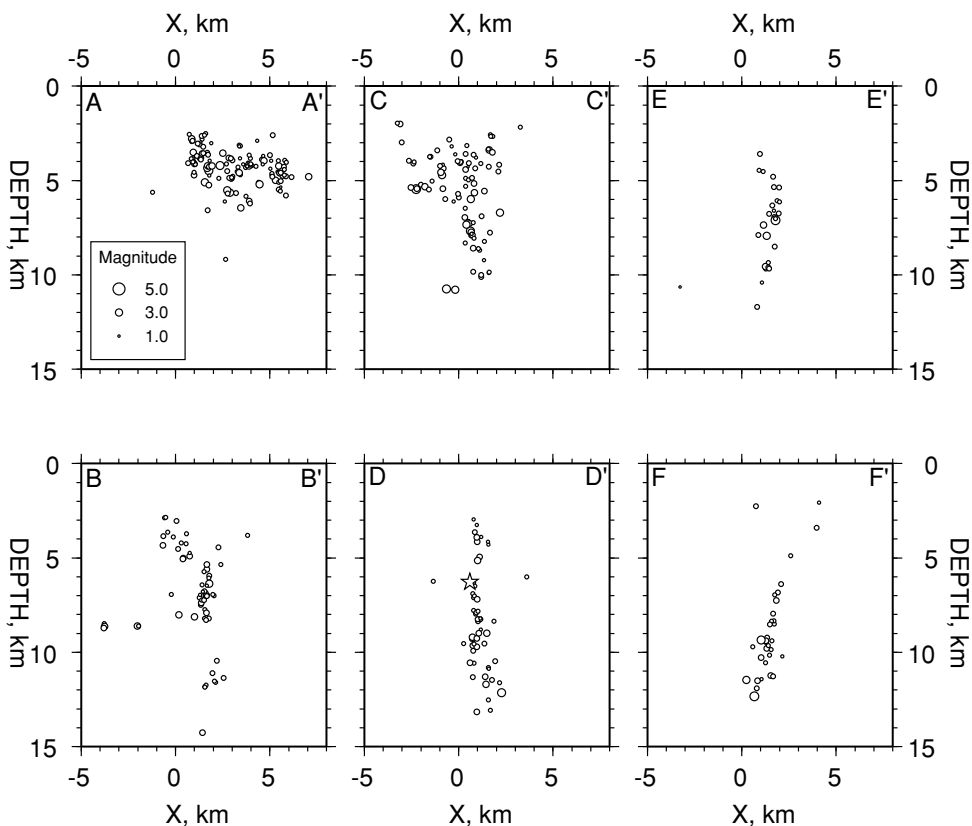

(c)

Fig. 9. (a) The cross section of the depth distribution of the aftershocks along the y-axis. (b) The epicentral distribution of the aftershocks determined simultaneously in the tomographic inversion. The y-axis is rotated anticlockwise from North by $30^{\circ}$. (c) The six cross sections of the depth distribution of the aftershocks along the lines $\mathrm{AA}^{\prime}$ to $\mathrm{FF}^{\prime}$ in (b). In these cross sections, events which occurred in the vicinity ( $\left.\pm 1 \mathrm{~km}\right)$ of the plane are plotted. The star indicates the starting point of the mainshock rupture.

The changes of the hypocenters relocated in the tomographic inversion relative to those relocated by the JHD method were at the most $0.2 \mathrm{~km}$ horizontally and -0.05 $-0.75 \mathrm{~km}$ downwards, for more than $90 \%$ of the analyzed aftershocks. Since the hypocenters changed little in the tomographic inversion, the decrease of the RMS of the travel time residuals $(0.089 \mathrm{~s}$ to $0.042 \mathrm{~s})$ was mostly due to the improvement of the velocity structure.

Ohmi et al. (2002) relocated the mainshock and aftershocks of the 2000 Western Tottori Earthquake with a JHD technique using data from telemetered stations (permanent stations and the temporary online stations, SMNK and MTC). They inverted the $P$ and $S$ travel time data for hypocenters, $1-\mathrm{D}$ velocity model and station corrections which were represented in a quadratic form of the hypocenter parameters (x, y, z). Fukuyama et al. (2003) relocated the mainshock and aftershocks with a double difference technique using data from permanent stations. For the epicentral distribution, our results had similar features to those of the other studies. However, the results by Fukuyama et al. (2003) showed that the depths of the aftershocks were deeper than those in our results. And the results by Ohmi et al. (2002) showed that the upper limit of the aftershock distribution became deeper to the northwest, while our results did not show such a trend. This indicates that the temporary stations just above the aftershock area greatly improved the accuracy of the depths of the aftershocks.

\section{Focal Mechanisms of Aftershocks}

Focal mechanisms of the aftershocks were analyzed using the method of Maeda (1992). The hypocenters, $P$ wave polarities, takeoff angles and azimuths of ray paths were available from the hypocenter determination described above. Because of the high density of the station distribution, the focal mechanisms of most events were well determined. The ambiguities of the solutions were very small, even though the magnitudes of the events were small $(\mathrm{Mj} \approx$ 1.7).

The resulting focal mechanisms and the $P$ axis directions are shown in Fig. 10. Following Yamanaka et al. (2002), we classified the focal mechanisms into four types: normal fault type with the plunge of the $P$ axis $>60^{\circ}$; reverse fault type with the plunge of the $T$ axis $>60^{\circ}$; strike-slip type with the plunge of the null axis $>45^{\circ}$; and the remaining (intermediate) types. More than $80 \%$ of the determined mechanisms are classified into the strike-slip type. Only a few reverse fault type events are found.

In general, the $P$ axes are approximately in a NW-SE direction. However, lateral variations of the dominant directions of the $P$ axes are found along the aftershock area. In the northern part, the $P$ axes are mostly in the NW-SE direction. In the area around the epicenter of the mainshock and the southern part, events with $P$ axes in a NW-SE direction and events with $P$ axes between E-W and ESEWNW directions co-exist. The NW-SE direction of $P$ axes is consistent with a mechanism with a fault plane parallel to the trend of the entire aftershock distribution, which is the same as obtained from a moment tensor inversion with the long period waveforms of the mainshock (Fukuyama et al., 2001). The E-W direction of $P$ axes agrees with the focal mechanism of the initial rupture of the mainshock, which was determined by the $P$ wave first motion polarities (Ohmi et al., 2002). In the southeastern end of the aftershock area, most events have $P$ axes within the E-W and ENE-WSW directions. In the area of off-fault induced seismicity the southwest from the main fault zone, the dominant direction 


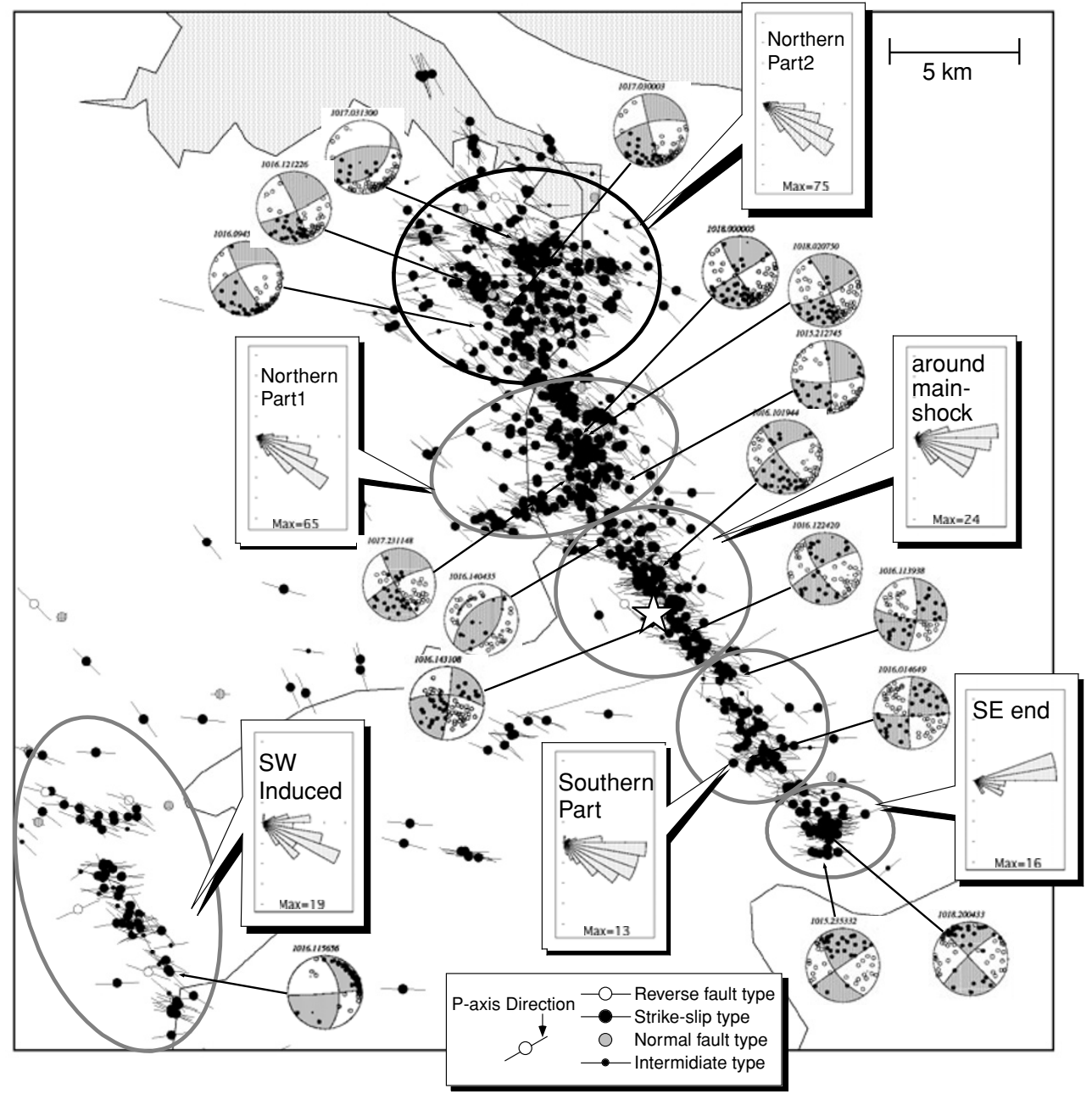

Fig. 10. Focal mechanisms and the directions of $P$ axes of the aftershocks. Types of the focal mechanisms are distinguished by the symbol for the epicenter, strike-slip types are solid circles, reverse fault types are open circles, normal fault types are gray circles, and intermediate types are small solid circles (see the text for the definition of the mechanism types). Bars through the epicenter circles represent the horizontal projections of the $P$ axes. Characteristic mechanisms for selected events are shown in upper hemisphere stereo projections. The rose diagrams show the relative number of the $P$ axes in $10^{\circ}$ sectors for the six regions surrounded by the ellipses. The max at the bottom of the rose diagrams indicated the maximum number in the sectors. The star indicates the starting point of the mainshock rupture.

of the $P$ axes is approximately ESE-WNW, although the precision of the mechanism determination is not as good as in the main fault zone.

\section{Discussion}

In this section, we discuss the relation between the resulting 3-D velocity structure and the aftershock distribution, the resistivity structure, and the geological structure.

Figure 11 shows the aftershock distribution with the perturbations of $V p, V s$ and $V p / V s$ at 2, 4, 6 and $8 \mathrm{~km}$ depths. The southeastern two-thirds of the NW-SE main branch of the aftershock distribution is located mostly in high $V p$ and $V s$ anomalies at 4, 6 and $8 \mathrm{~km}$ depths. However, looking closely at the aftershock distribution, few earthquakes occur in the high $V p$ anomalies larger than $4 \%$, such as areas $\mathrm{A}$ and $\mathrm{B}$. On the other hand the northwestern third of the main branch is located in low $V p$ anomalies at 4 and $6 \mathrm{~km}$ depths ( $\mathrm{H}$ and G, respectively) and in low $V s$ anomalies at $4 \mathrm{~km}$ depth. The NE-SW branch mentioned in section 6 is located at the southeastern edge of the low velocity zone.

The high $V p$ anomalies with relatively large perturba- tions, such as the areas A-F, also show high $V s$ anomalies and relatively high $V p / V s(\sim 1.75)$. In these areas the slip is small (Iwata and Sekiguchi, 2002). The aftershock distribution is terminated in the farthest southeastern high $V p$ anomaly. Geologically this high $V p$ anomaly corresponds to Late Cretaceous plutonic rocks between the Sangun metamorphic sequence, which are high pressure type rocks that were metamorphized in the Jurassic (Teraoka $e t$ al., 1996). These older plutonic and metamorphic rocks are distributed along the southern rim of early Paleogene plutonic rocks, namely the Neu Granitic Pluton (Iizumi et al., 1982; Teraoka et al., 1996). The older plutonic and metamorphic rocks correspond well to high velocity anomalies at $2 \mathrm{~km}$ depth, while the Neu Granitic Pluton can be characterized by low velocity anomalies. Therefore, the other deeper high $V p$ anomalies with high $V p / V s$ may be considered as plutonic or metamorphic rocks. They could be stronger than the surrounding materials and might behave like barriers to the mainshock rupture and the aftershock occurrence.

The low $V p$ anomalies located at $\mathrm{G}$ and $\mathrm{H}$ show low 


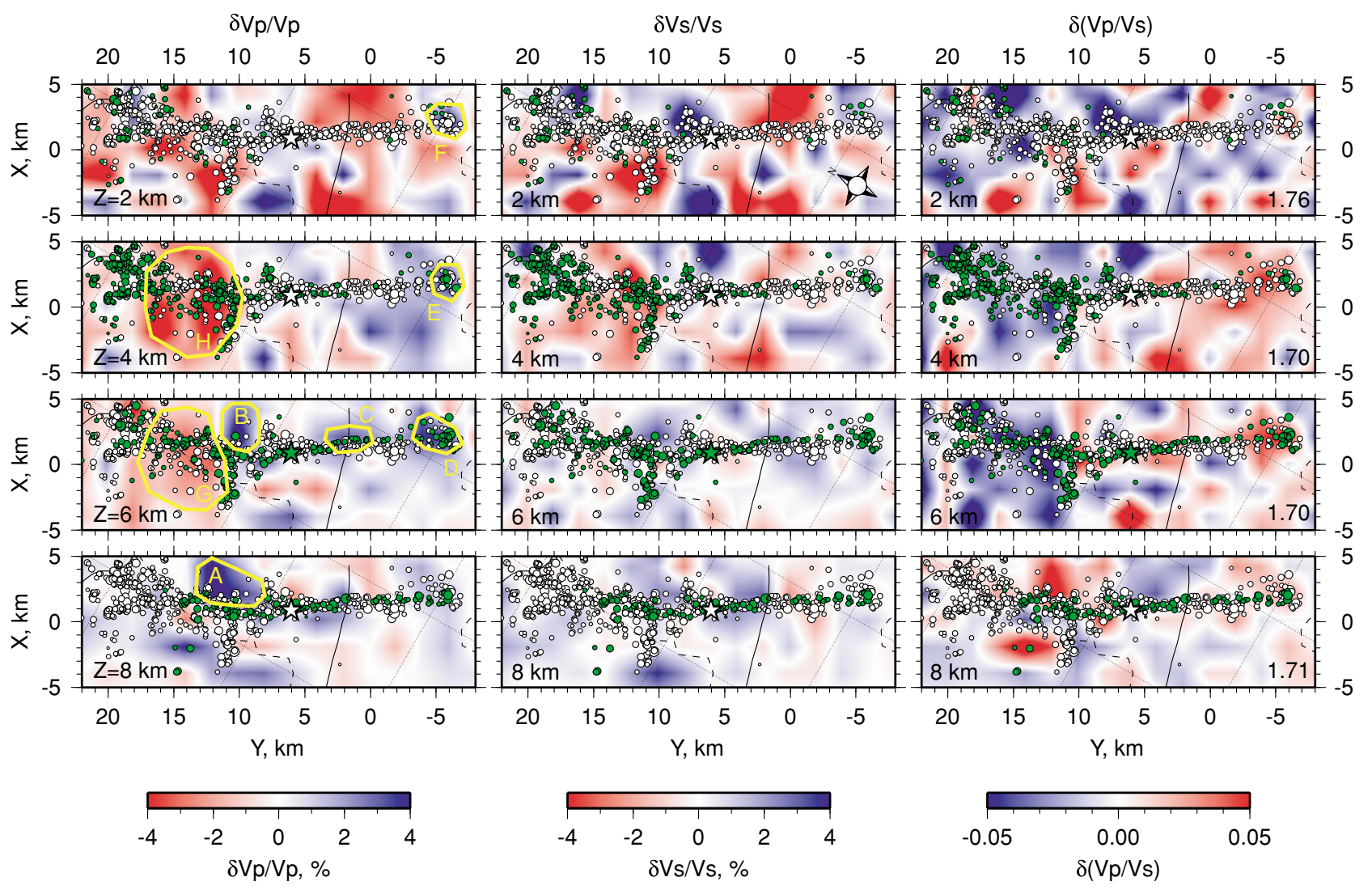

Fig. 11. Lateral heterogeneities of the resulting velocity structure at $2 \mathrm{~km}$ (the uppermost figures), $4 \mathrm{~km}$ (figures in the second row), $6 \mathrm{~km}$ (figures in the third row) and $8 \mathrm{~km}$ (the lowermost figures). The figures in the columns from the left to the right show $V p$ perturbations, $V s$ perturbations and $V p / V s$ perturbations. Open circles denote the epicentral distribution of the aftershocks. Green circles indicate the events which occurred in the vicinity $( \pm 1$ $\mathrm{km}$ ) of each depth slice. The star indicates the starting point of the mainshock rupture. The thin line denotes an active fault (Kamakurayama-nanpo Fault). Dashed lines indicate the borders of prefectures. See the text for the area A-H surrounded with the yellow lines.

$V p / V s(\sim 1.65)$. Geologically these low $V p$ anomalies correspond to non-alkali volcanic and pyroclastic rocks in the early to middle Miocene (Teraoka et al., 1996; Sakamoto et al., 1982). Therefore, the above mentioned NE-SW branch of the aftershock distribution is located at the farthest southeastern edge of the zone of non-alkali volcanic and pyroclastic rocks.

As mentioned above, the high $V p$ anomalies in the vicinity of the mainshock fault of the 2000 Western Tottori Earthquake showed $V p \approx 6.5 \mathrm{~km} / \mathrm{s}$ which was significantly higher than $V p(\sim 6.2 \mathrm{~km} / \mathrm{s})$ in the surrounding region at the same depths. It is expected that (repeated) mainshock faulting increased the degree of fractures in the vicinity of the fault, and as the result the $V p$ and $V s$ were decreased. However, it is difficult to explain that the velocities were increased by mainshock faulting. Furthermore, Figure 11 indicates that the velocity anomalies shown in Fig. 7 are distributed not only on the fault but also in volumes off the fault. In the farthest southeastern area of the aftershock distribution, where the high velocity anomalies were located near the surface, the anomalies corresponded well to high pressure type metamorphic rocks and Late Cretaceous plutonic rocks. These results strongly suggest that the velocity anomalies, which were found using the aftershock data, originate from the different geology and existed before the earthquake.

The resistivity structure has also been obtained near the source area of the 2000 Western Tottori Earthquake (Oshiman et al., 2004). comparing the velocity and the resistivity on a N-S cross section through the vicinity of the mainshock starting point, we found that the high and low velocity anomalies correspond quite well to the high and low resistivity anomalies, respectively. In the above paragraph we pointed out a possibility that the high velocity anomalies correspond to plutonic or metamorphic rocks, which might be strong and contain few cracks and less fluids. Consequently the high velocity anomalies show high resistivity.

Hirahara et al. (1992) investigated 3-D velocity structure in the source region of the 1984 Western Nagano Prefecture Earthquake. They found that the areas with large dislocations corresponded to those with relatively low velocities on the fault plane. This is the same relation we found for the 2000 Western Tottori Earthquake. Mikumo et al. (1987) showed that large dislocations occur in and around low velocity zones by numerical calculations of the fault rupture processes in inhomogeneous media.

Eberhart-Phillips et al. (1990) and Eberhart-Phillips and Michael (1993) investigated 3-D velocity structure in the Loma Prieta Earthquake region and the Parkfield region, respectively. They pointed out strong agreement between the seismic velocity and the resistivity distributions across the San Andreas Fault (SAF), as we found for the 2000 Western Tottori Earthquake. They also showed that the velocity structure changes greatly across the SAF. However, our re- 
sult indicates that the $V p$ and $V s$ were rather high in the vicinity of the mainshock fault and the velocity structure does not change across the fault plane of the 2000 Western Tottori Earthquake, as shown in Fig. 8. This can be due to the difference in the tectonic settings, where the SAF is a transform fault between the Pacific Plate and the North American Plate, while the fault of the 2000 Western Tottori Earthquake is an active fault which was first recognized by the occurrence of the earthquake. In the vicinity of a mature fault which has repeatedly caused large earthquakes, a broad fracture zone has been formed and can be recognized as a low velocity anomaly. Therefore, we think that the mainshock fault of the 2000 Western Tottori Earthquake represents young weak planes in a relatively homogeneous structure, instead of a boundary between different geological structures.

Thurber et al. (1997) found zones of low $V p$ and high $V p / V s(\geq 2.0)$ beneath the SAF. The high $V p / V s$ zones extend to a depth of about $6 \mathrm{~km}$ and cut across areas of very different $V p$ values. Therefore, they concluded that the high $V p / V s$ values are due to the presence of fluids. Zhao et al. (1996) found low $V p$ and $V s$ anomalies with high $V p / V s$ values near the hypocenter of the 1995 Kobe Earthquake. They suggested that the anomalies might be due to overpressurized, fluid-filled, fractured rock matrices and contribute to the nucleation of the mainshock. However, we did not find such high $V p / V s$ areas which indicated the presence of fluids on the fault plane of the 2000 Western Tottori Earthquake, as shown in Fig. 7. This disagreement might be due to the difference in the tectonic settings and the degree of maturity of the faults.

As mentioned in the section of the focal mechanisms, most of the aftershocks have strike-slip type focal mechanisms and $P$ axes approximately in a NW-SE direction for the 2000 Western Tottori Earthquake. On the contrary, for the 1995 Kobe Earthquake, aftershocks along the mainshock rupture zone showed various directions of the $P$ axes and variety in the mechanism types. The reverse fault types and the strike-slip types co-existed in narrow areas (Katao et al., 1997; Yamanaka et al., 2002). This difference might be due to differences in the degree of heterogeneity of the initial stress and strength distributions in the source regions of the two earthquakes.

\section{Conclusions}

High density aftershock observation of the 2000 Western Tottori Earthquake successfully reveal high resolution images of the 3-D $V p$ and $V s$ structure in and around the source region, as well as precise locations and focal mechanisms of the aftershocks.

The lateral distributions of $V p$ and $V s$ at $2 \mathrm{~km}$ depth have good correlations with geological structure. The depth distributions of $V p$ and $V s$ along the fault plane show that areas with high $V p$ and $V s$ anomalies $(>4 \%)$ and high $V p / V s(\sim 1.75)$ are located in patches of the central area and the southeastern edge of the aftershock distribution. These high velocity anomalies might correspond to plutonic and metamorphic rocks of the Jurassic to the Late Cretaceous. The cross sections also show that there exist low velocity anomalies at shallow depths $(2-4 \mathrm{~km})$ in the south- eastern area and at depths $(0-6 \mathrm{~km})$ in the northwestern area. The former might be the core of the Neu Granitic Pluton of the early Paleogene, while the latter might correspond to non-alkali volcanic and pyroclastic rocks of the early to middle Miocene.

The total slip during the mainshock is larger in the southeastern region than in the northwestern region of the aftershock distribution. In the southeast area the aftershocks are located in the vicinity of the fault plane, while in the northwest they spread out spatially at shallow depths. Furthermore, the slip is small on the high velocity patches and large in the shallow low velocity anomaly of the southeastern region.

The southwest branch of the aftershocks is located at the farthest southeastern edge of the low velocity anomaly, which might correspond to the non-alkali volcanic and pyroclastic rocks.

The high and low velocity anomalies agree quite well with the high and low resistivity anomalies, respectively. We suggest that the high velocity patches on the mainshock fault plane, which might correspond to older plutonic or metamorphic rocks, contain few cracks and little fluid, might be strong, and might like barriers to the mainshock rupture.

Finally, we conclude that pre-existing structural heterogeneities could control the rupture process of the mainshock and the occurrence of the aftershocks in the case of the 2000 Western Tottori Earthquake.

Acknowledgments. We are very grateful to Western General Office of Tottori Prefecture who allowed us to use a room as a base of the aftershock observation. Our thanks are also due to people in Western Tottori, Eastern Shimane and Northern Okayama Prefectures who allowed us to put seismometers and data loggers on their land. We thank Makoto Matsubara for his advices on retrieving data from DAT tapes. We benefited from the thoughtful reviews of Edi Kissling and Hiroaki Negishi and the suggestions of Eiichi Fukuyama, the editor. We used waveform data from the following permanent stations; IKUM, JKR, SAIJ (JMA); HINH, HKTH, MZKH, NITH, SGOH (NIED); NKR1 (ERI, Tokyo Univ.); KYT, QMT, SNT, TRT (RCEP, Kyoto Univ.). Generic Mapping Tool (Wessel and Smith, 1991) was used for drawing figures. This work was partially supported by Special Coordination Funds for Promoting Science and Technology, from Ministry of Education, Sport, Culture, Science and Technology (12800013).

The participants of this observation are listed below: S. Fujihara, Y. Fujisawa, Y Fujita, N. Hirano, M. Hirata, S. Itaba, K. Ito, T. Ito, Y. Kano, Y. Kase, H. Katao, M. Koizumi, Y. Maeda, T. Mizuno, J. Mori, T. Nakanishi, S. Nakao, K. Nishigami, S. Ohmi, K. Onoue, T. Shibutani, A. Shito, F. Takeuchi, T. Ueno, Y. Umeda, F. Yamashita, K. Yoshii, K. Yoshikawa, Y. Yukutake (Kyoto Univ.); N. Hirata, S. Ide, Y. Ichinose, Y. Iio, Y. Inoue, E. Kurashimo, S. Nakagawa, I. Ogino, K. Sakai, C. Wu (Univ. of Tokyo); Y. Asano, F. Hirose, S. Hori, T. Kono, T. Maeda, Y. Matsuda, J. Nakajima, A. Nakamura, K. Nida, T. Okada, T. Saito, Y. Suwa, T. Takahashi, H. Ueda, N. Ujigawa, N. Umino (Tohoku Univ.); K. Katsumata, N. Wada (Hokkaido Univ.); K. Asamori, A. Kuroki, R. Mita, O. P. Mishra, M. Nakamura, T. Nishino, F. Ochi, T. Ono, M. Salah, I. Serrano, D. Zhao (Ehime Univ.); A. Hasemi, T. Shibuya, K. Takizawa (Yamagata Univ.); R. Nishida (Tottori Univ.); T. Matsushima, K. Uehira (Kyushu Univ.). The affiliations of the participants at the time of the observation are shown in the parentheses.

Processings such as retrieving waveform data from DAT tapes, merging them into files, etc. were mainly done by T. Shibutani, N. Hirano, H. Katao, S. Ohmi, E. Kurashimo, K. Katsumata and T. 
Okada. Picking up the arrival times was done by T. Shibutani, $\mathrm{H}$. Katao, S. Nakao, N. Hirano, F. Takeuchi, T. Ueno, A. Shito, Y. Kano, T. Mizuno, K. Yoshikawa, Y. Maeda, M. Hirata, J. Mori, K. Nishigami, S. Fujihara. The 1-D and 3-D inversions of the travel time data were mainly done by T. Shibutani. The focal mechanism analysis was mainly done by $\mathrm{H}$. Katao.

\section{References}

Eberhart-Phillips, D., Three-dimensional P and S velocity structure in the Coalinga Region, California, J. Geophys. Res., 95, 15343-15363, 1990.

Eberhart-Phillips, D. and A. J. Michael, Three-dimensional velocity structure, seismicity, and fault structure in the Parkfield region, central California, J. Geophys. Res., 98, 15737-15758, 1993.

Eberhart-Phillips, D., V. F. Labson, W. D. Stanley, A. J. Michael, and B. D. Rodriguez, Preliminary velocity and resistivity models of the Loma Prieta earthquake region, Geophys. Res. Lett., 17, 1235-1238, 1990.

Fukuyama, E., M. Ishida, S. Horiuchi, H. Inoue, S. Hori, S. Sekiguchi, T. Eguchi, A. Kubo, H. Kawai, H. Murakami, S. Yamamoto, and K. Nonomura, NIED Seismic Moment Tensor Catalogue January-December, 2000, Technical Note of the National Research Institute for Earth Science and Disaster Prevention, 217, 1-131, 2001.

Fukuyama, E., W. L. Ellsworth, F. Waldhauser, and A. Kubo, Detailed fault structure of the 2000 Western Tottori, Japan, Earthquake sequence, Bull. Seism. Soc. Am., 93, 1468-1478, 2003.

Hirahara, K., N. Hirata, A. Ikami, H. Miyamachi, T. Yabuki, H. Aoki, I. Fujii, T. Haneda, A. Hasegawa, S. Hashimoto, N. Hirano, S. Horiuchi, Y. Iio, Y. Ishiketa, A. Ito, K. Ito, T. Kanazawa, S. Kaneshima, I. Karakama, M. Kobayashi, M. Koizumi, T. Kono, M. Kosuga, Y. Kurata, S. Kuriyama, A. Kuroiso, T. Matsuzawa, T. Mikumo, T. Mitsunami, K. Miura, Kazuaki Miura, R. Miyajima, M. Mizoue, T. Moriya, A. Nakajima, I. Nakamura, M. Nakamura, T. Nakamura, K. Nishigami, K. Oike, T. Okamoto, T. Okura, T. Ooida, T. Ouchi, T. Saeki, K. Sakai, T. Shibutani, M. Suzuki, S. Suzuki, M. Takahashi, A. Takagi, F. Takeuchi, T. Tanada, S. Tomita, T. Tsukuda, Y. Umeda, H. Wada, M. Yamada, A. Yamamoto, K. Yamashina, F. Yamazaki, and M. Yokohama, Threedimensional $\mathrm{P}$ and $\mathrm{S}$ wave velocity structure in the focal region of the 1984 Western Nagano Prefecture Earthquake, J. Phys. Earth, 40, 343360,1992

Hirata, N. and M. Matsu'ura, Maximum-likelihood estimation of hypocenter with origin time eliminated using nonlinear inversion technique, Phys. Earth Planet. Inter., 47, 50-61, 1987.

Iizumi, S. and Research Group for the Batholith in the San'in Zone, The Neu Granitic Pluton-Petrographical study on the batholith in the San'in Zone, Southwest Japan (Part 1)—, J. Geol. Soc. Jpn., 88, 299_ 310, 1982 (in Japanese with English abstract).

Iwata, T. and H. Sekiguchi, Source inversion of recent earthquakes using strong motion records, in a special issue on Strong Motion Prediction, Chikyu Monthly, 37, 47-55, 2002 (in Japanese).

Katao, H., N. Maeda, Y. Hiramatsu, Y. Iio, and S. Nakao, Detailed Mapping of Focal Mechanisms in/around the 1995 Hyogo-ken Nanbu Earthquake Rupture Zone, J. Phys. Earth, 45, 105-119, 1997.

Kissling, E., W. L. Ellsworth, D. Eberhart-Phillips, and U. Kradolfer, Initial reference models in local earthquake tomography, J. Geophys. Res., 99, 19635-19646, 1994.

Maeda, N., A method of determining focal mechanisms and quantifying the uncertainty of the determined focal mechanisms for microearthquakes, Bull. Seism. Soc. Am., 82, 2410-2429, 1992.

Mikumo, T., K. Hirahara, and T. Miyatake, Dynamical fault rupture processes in heterogeneous media, Techtonophysics, 144, 19-36, 1987.

Ohmi, S., K. Watanabe, T. Shibutani, S. Nakao, N. Hirano, A. Nakao, H. Takeuchi, F. Takeuchi, S. Miwa, A. Shito, A. Kim, and B. Enescu, The 2000 Tottori-ken Seibu Earthquake-Seismic activity derived from the compilation of DPRI, JMA and Hi-net data-, Annu. Disas. Prev. Res. Inst., Kyoto Univ., 44B-1, 273-282, 2001 (in Japanese with English abstract).

Ohmi, S., K. Watanabe, T. Shibutani, N. Hirano and S. Nakao, The 2000 Western Tottori Earthquake-Seismic activity revealed by the regional seismic networks—, Earth Planets Space, 54, 819-830, 2002.

Oike, K., On a list of hypocenters compiled by the Tottori Microearthquake Observatory, Zisin (J. Seismol. Soc. Jpn.), 28, 331-346, 1975 (in Japanese with English abstract).

Oshiman, N. and Research Group for Crustal Resistivity Structure 2001, Deep crustal resistivity structure in the focal region of the 2000 Western Tottori Earthquake, Abst. Annu. Conf. Disas. Prev. Res. Inst. 2003, P56, 2004 (in Japanese).

Sakamoto, T., N. Yamada, and Y. Suda, Geological map of Japan 1:200,000 Matsue and Taisha, Geological Survey of Japan, 1982.

Sawada, Y., T. Tokuoka, S. Yamauchi, Y. Sampei, and K. Nishimura, A newly discovered Pleistocene volcano in Miho Bay, along the axial zone of the Shinji Rift System, Southwest Japan, J. Geol. Soc. Jpn., 107, 392405, 2001 (in Japanese with English abstract).

Sekiguchi, H. and T. Iwata, Near-source ground motions controlled by source process in the case of the 2000 Tottoriken-Seibu earthquake, Program. Abst., Seism. Soc. Jpn., A73, 2001 (in Japanese).

Shibutani, T., S. Nakao, R. Nishida, F. Takeuchi, K. Watanabe, and Y. Umeda, Swarm-like seismic activity in 1989, 1990 and 1997 preceding the 2000 Western Tottori Earthquake, Earth Planets Space, 54, 831$845,2002$.

Teraoka, Y., H. Matsuura, H. Makimoto, F. Yoshida, M. Kamitani, T. Hiroshima, M. Komazawa, and R. Shichi, Geological map of Japan 1:200,000 Takahashi, Geological Survey of Japan, 1996.

Thurber, C. H., Earthquake locations and three-dimensional crustal structure in the Coyote Lake area, central California, J. Geophys. Res., 88, 8226-8236, 1983.

Thurber, C. H., Local earthquake tomography: velocities and Vp/Vstheory, in Seismic Tomography, edited by H. M. Iyer and K. Hirahara, 842 pp, Chapman and Hall, London, 1993.

Thurber, C., S. Roecker, W. Ellsworth, Y. Chen, W. Lutter, and R. Sessions, Two-dimensional seismic image of the San Andreas Fault in the Northern Gabilan Range, central California: Evidence for fluids in the fault zone, Geophys. Res. Lett., 24, 1591-1594, 1997.

Tottori Prefectural Government, Investigation of the underground structure in the area related to the 2000 Tottori Seibu Earthquake, 18 pp., Tottori Prefecture, Tottori, 2004 (in Japanese).

Tsukui, M., Temporal variation in chemical composition of phenocrysts and magmatic temperature at Daisen volcano, southwest Japan, J. Volcanol. Geotherm. Res., 26, 317-336, 1985.

Umeda, Y., K. Matsumura, T. Shibutani, S. Ohmi, and H. Katao, The 2000 Western Tottori Earthquake-Precursory swarm earthquake, main shock and aftershock-, J. JSNDS, 19, 501-512, 2001 (in Japanese with English abstract).

Wessel, P. and W. H. F. Smith, Free software helps map and display data, EOS Trans., Am. Geophys. Union, 72, 441, 1991.

Yamanaka, H., Y. Hiramasu and H. Katao, Spatial distribution of atypical aftershocks of the 1995 Hyogo-ken Nanbu earthquake, Earth Planets Space, 54, 933-945, 2002.

Zhao, D., H. Kanamori, H. Negishi, and D. Wiens, Tomography of the source area of the 1995 Kobe Earthquake: Evidence for fluids at the Hypocenter?, Science, 274, 1891-1894, 1996.

T. Shibutani (e-mail: shibutan@rcep.dpri.kyoto-u.ac.jp), H. Katao, and Group for the dense aftershock observations of the 2000 Western Tottori Earthquake 